Research Paper

\title{
Correlation of E-cadherin gene polymorphisms and epidermal growth factor receptor mutation in lung adenocarcinoma
} \author{
Yang1,8凶, Thomas Chang-Yao Tsao ${ }^{9,10 \bowtie}$ \\ 1. Institute of Medicine, Chung Shan Medical University, Taichung, Taiwan \\ 2. Department of Pulmonary Medicine, Buddhist Tzu Chi General Hospital, Taipei Branch, New Taipei City, Taiwan \\ 3. Cancer Research Center, Changhua Christian Hospital, Changhua, Taiwan \\ 4. Graduate Institute of Biomedical Sciences, China Medical University, Taichung, Taiwan \\ 5. Department of Chest Medicine, Cheng-Ching General Hospital, Taichung, Taiwan \\ 6. School of Medical Laboratory and Biotechnology, Chung Shan Medical University, Taichung, Taiwan \\ Department of Biochemistry and Molecular Biology, University of Massachusetts, Amherst, United States \\ 8. Department of Medical Research, Chung Shan Medical University Hospital, Taichung, Taiwan \\ 9. School of Medicine, Chung Shan Medical University, Taichung, Taiwan \\ 10. Division of Chest, Department of Internal Medicine, Chung Shan Medical University Hospital, Taichung, Taiwan \\ "These authors contributed equally to the work.
}

Chun-Yao Huang ${ }^{1,2^{*}}$, Ming-Ju Hsieh $1,3,4^{*}$, Tu-Chen Liu ${ }^{1,5}$, Whei-Ling Chiang ${ }^{6}$, Ming-Che Liu ${ }^{7}$, Shun-Fa

$\square$ Corresponding authors: Thomas Chang-Yao Tsao MD, PhD. or Shun-Fa Yang, PhD. Institute of Medicine, Chung Shan Medical University, 110, Section 1, Chien-Kuo N. Road, Taichung, Taiwan, ROC. Fax: 886-4-24723229. E-mail: his885889@gmail.com (Tsao TC); ysf@csmu.edu.tw (Yang SF)

(c) Ivyspring International Publisher. This is an open access article distributed under the terms of the Creative Commons Attribution (CC BY-NC) license (https:// creativecommons.org/licenses/by-nc/4.0/). See http://ivyspring.com/terms for full terms and conditions.

Received: 2017.11.27; Accepted: 2018.04.12; Published: 2018.05.22

\begin{abstract}
Epithelial-mesenchymal transition (EMT) was recently discovered related to the efficacy of epidermal growth factor receptor-tyrosine kinase inhibitors (EGFR-TKIs) in NSCLC patients and cell lines. In this study, we aimed to explore the association among the E-cadherin gene $(C D H I)$ genetic variants, TK-domain mutations of EGFR, and clinicopathologic characteristics in patients with lung adenocarcinoma. A total of 280 patients with lung adenocarcinoma were recruited between years 2012 and 2015. All subjects underwent the analysis of $C D H I$ genetic variants (rs16260 and rs9929218) by real-time polymerase chain reaction (PCR) genotyping. The results showed that $C A$ and $C A+A A$ genotypes of $C D H I$ single nucleotide polymorphism (SNP) rs 16260 were significantly reverse associated with EGFR mutation type (Adjusted odds ratio $(A O R)=0.43,95 \% \mathrm{Cl}=$ $0.20-0.92$ and $A O R=0.46,95 \% \mathrm{Cl}=0.22-0.96$, respectively) in female lung adenocarcinoma patients. Moreover, the significantly reverse associations between CA and CA + AA genotypes of CDHI rs 16260 and EGFR hotspot mutations, namely L858R mutation and exon 19 in-frame deletion, were also demonstrated among female patients. Besides, $\mathrm{CA}+\mathrm{AA}$ genotype of $\mathrm{CDHI}$ rs 16260 was noted significantly reverse associated with the tumor sizes $(\mathrm{OR}=0.31,95 \% \mathrm{Cl}=0.12-0.80 ; \mathrm{p}=0.012)$. In conclusion, our results suggested that $\mathrm{CDHI}$ variants are significantly reverse associated with mutation of EGFR tyrosine kinase, especially among the female patients with lung adenocarcinoma. The $C D H I$ variants might contribute to pathological development in lung adenocarcinoma.
\end{abstract}

Key words: Adenocarcinoma; E-cadherin; $C D H 1$ gene; Polymorphism; Genetic variants; Epidermal growth factor receptor

\section{Introduction}

Lung cancer is the most common cancer worldwide and also represented the most common death in Taiwan. Based on the National Health Insurance Research Database published in Taiwan, the 5-year survival rate of lung cancer patients was $15.9 \%$ [1]. The $2015 \mathrm{WHO}$ classification relies on a greater extent of immunohistochemical characterizeation, which allows for precise subtyping, conduction of appropriate treatment strategy, and predicting clinical course. Moreover, the molecular characterization of patients with non-small cell lung cell (NSCLC) is resulting in the use of agents with high levels of 
antitumor activity, particularly for those with driver mutations [2]. The most notorious ones are the mutations in the epidermal growth factor receptor (EGFR) and rearrangement of the anaplastic lymphoma kinase $(A L K)$ gene or ROS1 gene, and mutation in BRAF V600E. Mutations in the EGFR tyrosine kinase are noticed in lung adenocarcinoma and occur more frequently in females and non-smokers [3]. In Asia, the incidence of EGFR mutation goes even up to $62 \%$ [4].

E-cadherin (CDH1 gene) is a $\mathrm{Ca}^{2+}$ dependent homotypic cell adhesion molecule (CAM) that is important in the formation of adherens junctions to bind cells altogether and functions as a binding partner for $\beta$-catenin [5]. The E-cadherin plays a key role in cellular adhesion, and its down-regulation is potentially important and highly associated with greater tumor metastasis [6-10]. E-cadherin is regarded as an important factor for Epithelialmesenchymal transition (EMT), which is the critical step for cancer metastasis [11, 12].

Of recent knowledge, EMT is associated with the mutant status of EGFR and the efficacy of EGFR-tyrosine kinase inhibitors (TKIs) in lung cancer cell lines as well as NSCLC patients. Also, the reduction of E-cadherin expression predicts worse overall survival (OS) and disease-free survival/ progression-free survival (DFS/PFS) in patients with NSCLC $[13,14]$. Furthermore, decreased expression of E-cadherin was associated with decreased sensitivity to EGFR-TKIs, whereas high E-cadherin expression improved tumor cells' sensitivity to EGFR-TKIs [15]. However, the correlation between $\mathrm{CDH} 1$ gene polymorphisms and EGFR mutations of lung adenocarcinoma has not been well-studied. In this study, we hypothesized that the genetic polymorphisms of CDH1 (rs16260 and rs9929218) may have an effect on the TK-domain mutations of EGFR in patients with lung adenocarcinoma.

\section{Material and Methods}

\section{Study Population}

Between years 2012 and 2015, a total of 280 patients with lung adenocarcinoma at Cheng-Ching General Hospital in Taichung, Taiwan were recruited. The study was approved by the Institutional Review Board of Cheng-Ching General Hospital (No. HP120009; 22 September 2012). All enrolled patients provided signed informed consent to participate in this study.

\section{Study Variables}

The main endpoint of the present study was the prevalence of EGFR mutation among these lung adenocarcinoma patients, and its association with
E-cadherin (CDH1) genotypes. We selected two CDH1 SNPs, including rs16260 (-160, C/A) in the promoter region and the intron 2 variant rs9929218 based on their potential involvement in the various cancer types [16-20]. Different associating factors relating to the mutations in EGFR were considered and analyzed as previously described [21, 22]. Data obtained from medical record of each patient included demographics (age, gender), tobacco smoking status, and tumor staging and differentiation.

\section{Patients Specimens for Genomic DNA Extraction and E-cadherin (CDHI) Genotyping}

Venipuncture was performed and withdrawn blood from each participant into Vacutainer blood collection tubes containing EDTA and stored at $4^{\circ} \mathrm{C}$. Genomic DNA was extracted from QIAamp DNA blood mini kits according to the manufacturer's instructions as previously described [23]. Allelic discrimination of CDH1 rs16260 (C_11934298_10) and rs9929218 (C_11509221_10) gene polymorphisms was assessed with the ABI StepOne ${ }^{\mathrm{TM}}$ Real-Time PCR System (Applied Biosystems, Foster City, CA, USA) and analyzed using SDS version 3.0 software (Applied Biosystems) with the TaqMan assay.

\section{Statistical Analysis}

Categorical variables, including demographics, smoking status, tumor characteristics, and genotypes polymorphisms, were summarized as number and percentage by EGFR mutation status; continuous variables were expressed as mean and standard deviation. The distributions of demographics, clinical characteristics and genotype frequencies among lung adenocarcinoma patients, as well as clinicopathological features in different genotypes, were analyzed with a $x^{2}$-test. A p-value of $<0.05$ indicated statistically significant.

\section{Results}

\section{Characteristics of Study Population}

This study included a total of 280 patients, 127 males and 153 females with a mean age of 65 years, for analysis. The baseline demographics and clinical characteristic of enrolled patients were shown in Table 1. There were 111 (39.6\%) and 169 (60.4\%) patients in the EGFR wild-type and mutation type groups, respectively. These two groups differed with respect to gender, tobacco smoking status, and tumor differentiation $(\mathrm{p}<0.001)$. The EGFR mutation type group, compared with subjects in the EGFR wild-type group, were predominantly female $(64.5 \%$ vs. $39.6 \%$, respectively), non-smoker status (77.5\% vs. $45.0 \%)$, and mostly well-differentiated $(12.4 \%$ vs. $7.2 \%)$ and moderately-differentiated tumor $(81.7 \%$ vs. $72.1 \%)$. 
Table 1. Baseline demographic and clinical characteristics of patients with lung adenocarcinoma by EGFR mutation status $(\mathrm{N}=280)$

\begin{tabular}{|c|c|c|c|}
\hline Variable & $\begin{array}{l}\text { Wild-type } \\
(\mathrm{N}=111)\end{array}$ & $\begin{array}{l}\text { EGFR mutation } \\
(\mathrm{N}=169)\end{array}$ & p-value \\
\hline \multicolumn{4}{|l|}{ Age, n (\%) } \\
\hline$<30$ & $1(0.9 \%)$ & $1(0.6 \%)$ & \multirow[t]{6}{*}{$p=0.657$} \\
\hline $30-39$ & $3(2.7 \%)$ & $2(1.2 \%)$ & \\
\hline $40-49$ & $11(9.9 \%)$ & $16(9.5 \%)$ & \\
\hline $50-59$ & $21(18.9 \%)$ & $44(26.0 \%)$ & \\
\hline $60-69$ & $26(23.4 \%)$ & $31(18.3 \%)$ & \\
\hline$\geq 70$ & $49(44.1 \%)$ & $75(44.4 \%)$ & \\
\hline Mean \pm SD & $65.36 \pm 13.42$ & $65.76 \pm 13.57$ & $\mathrm{p}=0.810$ \\
\hline \multicolumn{4}{|l|}{ Gender, $\mathrm{n}(\%)$} \\
\hline Male & $67(60.4 \%)$ & $60(35.5 \%)$ & \multirow[t]{2}{*}{$\mathrm{p}<0.001$} \\
\hline Female & $44(39.6 \%)$ & $109(64.5 \%)$ & \\
\hline \multicolumn{4}{|c|}{ Tobacco smoking, n (\%) } \\
\hline Non-smoker & $50(45.0 \%)$ & $131(77.5 \%)$ & \multirow[t]{2}{*}{$\mathrm{p}<0.001$} \\
\hline Smoker & $61(55.0 \%)$ & $38(22.5 \%)$ & \\
\hline Pack-years \pm SD & $46.32+28.21$ & $19.94+23.83$ & $\mathrm{p}<0.001$ \\
\hline \multicolumn{4}{|c|}{ Tumor AJCC staging, $\mathbf{n}(\%)$} \\
\hline IA & $11(9.9 \%)$ & $17(10.1 \%)$ & \multirow[t]{7}{*}{$\mathrm{p}=0.570$} \\
\hline IB & $9(8.1 \%)$ & $23(13.6 \%)$ & \\
\hline IIA & $5(4.5 \%)$ & $7(4.1 \%)$ & \\
\hline IIB & $1(0.9 \%)$ & $0(0 \%)$ & \\
\hline IIIA & $10(9.0 \%)$ & $11(6.5 \%)$ & \\
\hline IIIB & $17(15.3 \%)$ & $19(11.2 \%)$ & \\
\hline IV & $58(52.3 \%)$ & $92(54.4 \%)$ & \\
\hline \multicolumn{4}{|c|}{ Tumor differentiation, $\mathrm{n}(\%)$} \\
\hline Well & $8(7.2 \%)$ & $21(12.4 \%)$ & \multirow[t]{3}{*}{$\mathrm{p}=0.001$} \\
\hline Moderate & $80(72.1 \%)$ & $138(81.7 \%)$ & \\
\hline Poor & $23(20.7 \%)$ & $10(5.9 \%)$ & \\
\hline
\end{tabular}

\section{Distribution of CDHI Genotypes of Study Population and Its Association with EGFR Mutation by Gender Difference}

The distribution frequency of $C D H 1$ genotypes (rs16260 and rs9929218) of patients with lung adenocarcinoma was shown in Table 2. The alleles with the highest distribution frequency for rs16260 and rs9929218 in the enrolled patients were homozygous $\mathrm{C} / \mathrm{C}$ and homozygous $\mathrm{G} / \mathrm{G}$ for both EGFR wild-type and mutation type groups, respectively. After adjusting for variance, there was no significant difference between the wild-type and mutation type of EGFR and polymorphisms of the CDH1 genotypes in rs16260 and rs9929218, when compared with wild-type individuals.

To elucidate the association between the polymorphism of $C D H 1$ gene and EGFR mutations in different gender, the distribution frequency of $C D H 1$ single nucleotide polymorphism (SNP) (rs16260 and rs9929218) of EGFR wild-type and mutation type in lung adenocarcinoma patients was estimated in Table 2. In females, CA and CA + AA genotypes of CDH1 rs16260 were significantly reverse associated with EGFR mutation type (AOR $=0.43,95 \% \mathrm{CI}=0.20-0.92$ and $\mathrm{AOR}=0.46,95 \% \mathrm{CI}=0.22-0.96$, respectively). Hence, further analyses were focused on the association between the polymorphism of $C D H 1$ gene and EGFR hotspot mutations in female patients with lung adenocarcinoma.

\section{Association between Polymorphisms of $\mathrm{CDHI}$ genotypes and EGFR Hotspot Mutations among the Female Lung Adenocarcinoma Patients}

Table 3 showed the association between the polymorphisms of $C D H 1$ and the EGFR hotspot mutation in the female patients. Also, the significantly reverse associations between $\mathrm{CA}$ and $\mathrm{CA}+\mathrm{AA}$ genotypes of $\mathrm{CDH1}$ rs16260 and EGFR hotspot mutations, namely L858R mutation $(\mathrm{OR}=0.40,95 \%$ $\mathrm{CI}=0.18-0.90$ and $\mathrm{OR}=0.44,95 \% \mathrm{CI}=0.20-0.97$, respectively) and exon 19 in-frame deletion (OR = $0.39,95 \% \mathrm{CI}=0.16-0.95$ and $\mathrm{OR}=0.41,95 \% \mathrm{CI}=$ 0.17-0.97, respectively), were demonstrated.

Table 2. Distribution frequency of $\mathrm{CDHI}$ genotypes of patients with lung adenocarcinoma and multiple logistic regression analysis of EGFR mutation association

\begin{tabular}{|c|c|c|c|c|c|c|c|c|c|}
\hline \multirow[b]{2}{*}{$\begin{array}{l}\text { Genotypes } \\
\text { SNP }\end{array}$} & \multicolumn{3}{|c|}{ All cases $(\mathrm{N}=\mathbf{2 8 0})$} & \multicolumn{3}{|c|}{ Male (N=127) } & \multicolumn{3}{|c|}{ Female $(\mathrm{N}=153)$} \\
\hline & $\begin{array}{c}\text { Wild type } \\
(\mathrm{N}=111) \\
\text { n (\%) }\end{array}$ & $\begin{array}{c}\text { Mutation type } \\
(\mathrm{N}=169) \\
\mathrm{n}(\%)\end{array}$ & $\begin{array}{c}\text { AOR } \\
(95 \% \mathrm{CI})\end{array}$ & $\begin{array}{c}\text { Wild type } \\
(\mathrm{N}=67) \\
\text { n (\%) }\end{array}$ & $\begin{array}{c}\text { Mutation type } \\
(\mathrm{N}=60) \\
n(\%)\end{array}$ & $\begin{array}{c}\text { AOR } \\
(95 \% \text { CI })\end{array}$ & $\begin{array}{c}\text { Wild type } \\
(\mathrm{N}=44) \\
\mathrm{n}(\%)\end{array}$ & $\begin{array}{c}\text { Mutation } \\
\text { type }(\mathrm{N}=109) \\
\mathrm{n}(\%)\end{array}$ & $\begin{array}{c}\text { AOR } \\
(95 \% \mathrm{CI})\end{array}$ \\
\hline \multicolumn{10}{|c|}{ CDH1 rs16260 } \\
\hline $\mathrm{CC}$ & $55(49.5 \%)$ & $90(53.3 \%)$ & 1.00 & $38(56.7 \%)$ & $26(43.3 \%)$ & 1.00 & $17(38.6 \%)$ & $64(58.7 \%)$ & 1.00 \\
\hline CA & $49(44.1 \%)$ & $70(41.4 \%)$ & $0.90(0.53-1.53)$ & $24(35.8 \%)$ & $31(51.7 \%)$ & $1.95(0.92-4.14)$ & $25(56.8 \%)$ & $39(35.8 \%)$ & $0.43(0.20-0.92)$ \\
\hline AA & $7(6.3 \%)$ & $9(5.3 \%)$ & $0.81(0.27-2.45)$ & $5(7.5 \%)$ & $3(5.0 \%)$ & $0.90(0.19-4.31)$ & $2(4.6 \%)$ & $6(5.5 \%)$ & $0.72(0.13-3.90)$ \\
\hline $\mathrm{CA}+\mathrm{AA}$ & $56(50.5 \%)$ & $79(46.7 \%)$ & $0.89(0.54-1.48)$ & $29(43.3 \%)$ & $34(56.7 \%)$ & $1.77(0.85-3.65)$ & $27(61.4 \%)$ & $45(41.3 \%)$ & $0.46(0.22-0.96)$ \\
\hline \multicolumn{10}{|c|}{ CDH1 rs9929218 } \\
\hline GG & $68(61.3 \%)$ & $108(63.9 \%)$ & 1.00 & $43(64.2 \%)$ & $34(56.7 \%)$ & 1.00 & $25(56.8 \%)$ & $74(67.9 \%)$ & 1.00 \\
\hline GA & $41(36.9 \%)$ & $56(33.1 \%)$ & $0.87(0.51-1.49)$ & $23(34.3 \%)$ & $25(41.7 \%)$ & $1.37(0.65-2.89)$ & $18(40.9 \%)$ & $31(28.4 \%)$ & $0.54(0.25-1.15)$ \\
\hline AA & $2(1.8 \%)$ & $5(3.0 \%)$ & $1.17(0.21-6.57)$ & $1(1.5 \%)$ & $1(1.6 \%)$ & $0.99(0.05-18.34)$ & $1(2.3 \%)$ & $4(3.7 \%)$ & $1.14(0.12-10.79)$ \\
\hline $\mathrm{GA}+\mathrm{AA}$ & $43(38.7 \%)$ & $61(36.1 \%)$ & $0.89(0.52-1.50)$ & $24(35.8 \%)$ & $26(43.3 \%)$ & $1.36(0.65-2.83)$ & $19(56.8 \%)$ & $35(32.1 \%)$ & $0.57(0.27-1.20)$ \\
\hline
\end{tabular}

The AORs with $95 \%$ CIs were estimated by multiple logistic regression models after controlling for age and smoking.

Note: Bold text indicated a significant association with $\mathrm{p}$ value $<0.05$.

Abbreviations: SNP, single nucleotide polymorphism; AOR, adjusted odds ratio; CI, confidence interval. 
Table 3. The associations between the polymorphisms of $\mathrm{CDHI}$ and the EGFR hotspot mutations in female patients with lung adenocarcinoma.

\begin{tabular}{|c|c|c|c|c|c|}
\hline \multirow[b]{2}{*}{ Genotypes } & \multicolumn{3}{|c|}{ Wild-type L858R } & \multicolumn{2}{|c|}{ Exon 19 in-frame deletion } \\
\hline & $\begin{array}{l}(\mathrm{N}=44) \\
\mathrm{n}(\%)\end{array}$ & $\begin{array}{l}\mathrm{N}=61) \\
\mathrm{n}(\%)\end{array}$ & $\begin{array}{l}\text { OR } \\
(95 \% \text { CI) }\end{array}$ & $\begin{array}{l}(\mathrm{N}=43) \\
\mathrm{n}(\%)\end{array}$ & $\begin{array}{l}\text { OR } \\
(95 \% \text { CI) }\end{array}$ \\
\hline \multicolumn{6}{|l|}{$\begin{array}{l}\text { CDH1 } \\
\text { rs16260 }\end{array}$} \\
\hline CC & $17(38.6 \%)$ & $36(59.0 \%)$ & 1.00 & $26(60.5 \%)$ & 1.00 \\
\hline CA & $25(56.8 \%)$ & $21(34.4 \%)$ & $\begin{array}{l}0.40 \\
(0.18-0.90)\end{array}$ & $15(34.9 \%)$ & $\begin{array}{l}0.39 \\
(0.16-0.95)\end{array}$ \\
\hline AA & $2(4.6 \%)$ & $4(6.6 \%)$ & $\begin{array}{l}0.94 \\
(0.16-5.67)\end{array}$ & $2(4.6 \%)$ & $\begin{array}{l}0.65 \\
(0.08-5.10)\end{array}$ \\
\hline $\mathrm{CA}+\mathrm{AA}$ & $27(61.4 \%)$ & $25(41.0 \%)$ & $\begin{array}{l}0.44 \\
(0.20-0.97)\end{array}$ & $17(39.5 \%)$ & $\begin{array}{l}0.41 \\
(0.17-0.97)\end{array}$ \\
\hline \multicolumn{6}{|l|}{$\begin{array}{l}\text { CDH1 } \\
\text { rs9929218 }\end{array}$} \\
\hline GG & $25(56.8 \%)$ & $41(67.2 \%)$ & 1.00 & $29(67.4 \%)$ & 1.00 \\
\hline GA & $18(40.9 \%)$ & $17(27.9 \%)$ & $\begin{array}{l}0.58 \\
(0.25-1.32)\end{array}$ & $13(30.2 \%)$ & $\begin{array}{l}0.62 \\
(0.26-1.52)\end{array}$ \\
\hline AA & $1(2.3 \%)$ & $3(4.9 \%)$ & $\begin{array}{l}1.83 \\
(0.18-18.56\end{array}$ & $1(2.3 \%)$ & $\begin{array}{l}0.86 \\
(0.05-14.51)\end{array}$ \\
\hline $\mathrm{GA}+\mathrm{AA}$ & $19(43.2 \%)$ & $20(32.8 \%)$ & $\begin{array}{l}0.64 \\
(0.29-1.43)\end{array}$ & $14(32.6 \%)$ & $\begin{array}{l}0.64 \\
(0.27-1.52)\end{array}$ \\
\hline
\end{tabular}

Note: bold text indicated a significant association with $\mathrm{p}$ value $<0.05$.

Abbreviations: SNP, single nucleotide polymorphism; OR, odds ratio; $\mathrm{CI}$, confidence interval.

\section{Association between CDHI SNP rs16260 and Tumor Classification among Male Lung Adenocarcinoma Patients}

The AJCC Tumor, Node, Metastasis (TNM) staging system for lung cancer (NSCLC) is an internationally accepted system to describe the extent of disease [24]. It combines features of the tumor into disease stage groups that correlate with survival and are linked to recommendations for treatment, as well as an indicator of prognosis. In this study, we further investigated the association between polymorphisms of $C D H 1$ gene and clinicopathologic characteristics among male patients with lung adenocarcinoma. As shown in Table 4, CA + AA genotype of CDH1 rs16260 was noted significantly reverse associated with the " $\mathrm{T}$ " classification (primary tumor size and extension) based on eighth edition of AJCC TNM staging system $(\mathrm{OR}=0.31,95 \% \mathrm{CI}=0.12-0.80 ; \mathrm{p}=$ 0.012). Furthermore, while stratified male patients based on EGFR mutation status, consistent reverse association was seen in the mutation type male patients $(\mathrm{OR}=0.20,95 \% \mathrm{CI}=0.04-0.99 ; \mathrm{p}=0.037)$. These findings indicated that the polymorphisms of CDH1 rs16260 may be associated with the tumor size and extension of lung cancer.

\section{Discussion}

Our study investigated 280 patients with lung adenocarcinoma, and the role of E-cadherin (CDH1) gene polymorphism in regards to the EGFR mutation status, as well as a possible prognostic marker for tumor invasiveness and metastasis and predictive marker for the resistance of EGFR-TKI therapy. The significance of E-cadherin (CDH1) polymorphism, as an important epithelial marker/factor of EMT, have been well-studied and established in several human cancers, such as breast cancer [25, 26], gastric cancer [27], pancreatic cancer, ovarian cancer [28, 29], prostate cancer [26], esophageal squamous cell carcinoma [30], head and neck cancer [31] and skin cancer [32-34]. Regard to lung cancers, though E-cadherin is highly associated with risk of NSCLC carcinogenesis $[14,35,36]$, particular adenocarcinoma, the mutant status of EGFR, the efficacy of EGFR-TKIs therapy [37], and survival prognosis, no study exploring the relationship between $C D H 1$ gene polymorphisms and the mutations of EGFR of lung cancers was conducted. To our best knowledge, this is the first time discovering the statistically significant association between CDH1 SNP rs16260 variant types (CA and CA + AA genotypes) and hotspot mutations (in-frame deletion mutation in exon 19 and L858R mutation) of EGFR, especially in the female lung adenocarcinoma patients.

Table 4. The associations between polymorphic genotypes of $\mathrm{CDHI}$ rs16260 and clinicopathologic characteristics of male patients with lung adenocarcinoma.

\begin{tabular}{|c|c|c|c|c|}
\hline \multirow[b]{2}{*}{$\begin{array}{l}\text { Variable genotypic } \\
\text { frequencies }\end{array}$} & \multicolumn{4}{|c|}{ Tumor AJCC "T" Classification } \\
\hline & $\begin{array}{l}\text { T1 \& below } \\
\text { n (\%) }\end{array}$ & $\begin{array}{l}\text { T2 \& above } \\
\text { n (\%) }\end{array}$ & $\begin{array}{l}\text { OR } \\
(95 \% \mathrm{CI})\end{array}$ & p value \\
\hline All cases $(\mathrm{N}=127)$ & $(\mathrm{N}=25)$ & $(\mathrm{N}=102)$ & & \\
\hline \multicolumn{5}{|l|}{ CDH1 rs16260 } \\
\hline $\mathrm{CC}$ & $7(28.0 \%)$ & $57(55.9 \%)$ & 1.00 & \\
\hline $\mathrm{CA}+\mathrm{AA}$ & $18(72.0 \%)$ & $45(44.1 \%)$ & $0.31(0.12-0.80)$ & $\mathrm{p}=0.012$ \\
\hline $\begin{array}{l}\text { EGFR Wild type } \\
(N=67)\end{array}$ & $(\mathrm{N}=13)$ & $(\mathrm{N}=54)$ & & \\
\hline \multicolumn{5}{|l|}{$C D H 1$ rs16260 } \\
\hline $\mathrm{CC}$ & $5(38.5 \%)$ & $33(61.1 \%)$ & 1.00 & \\
\hline $\mathrm{CA}+\mathrm{AA}$ & $8(61.5 \%)$ & $21(38.9 \%)$ & $0.40(0.12-1.38)$ & $p=0.139$ \\
\hline $\begin{array}{l}\text { EGFR Mutation type } \\
(\mathrm{N}=60)\end{array}$ & $(\mathrm{N}=12)$ & $(\mathrm{N}=48)$ & & \\
\hline \multicolumn{5}{|l|}{$C D H 1$ rs16260 } \\
\hline $\mathrm{CC}$ & $2(16.7 \%)$ & $24(50.0 \%)$ & 1.00 & \\
\hline $\mathrm{CA}+\mathrm{AA}$ & $10(83.3 \%)$ & $24(50.0 \%)$ & $0.20(0.04-0.99)$ & $\mathrm{p}=\mathbf{0 . 0 3 7}$ \\
\hline
\end{tabular}

Note: bold text indicated a significant association with $\mathrm{p}$ value $<0.05$.

Abbreviations: SNP, single nucleotide polymorphism; OR, odds ratio; CI, confidence interval.

Advanced NSCLCs that contains characteristic mutations in EGFR are highly sensitive to EGFR-TKIs. The previous study has reported that EGFR mutation was more prevalent in adenocarcinoma than other types of NSCLCs, as well as female and non-smokers [3]. The Asian population has the highest incidence of EGFR mutation in the world [4]. In Taiwan, Hsu et al. performed a study based on the National Taiwan Lung Cancer Registry and detected the EGFR mutation rate higher than $50 \%$ [38]. Indeed, as shown in our results, higher frequency of EGFR mutation type was 
observed in the female patients (female vs. male $=$ $64.5 \%$ vs. $35.5 \%$ ) and in non-smokers (non-smoker vs. smoker $=77.5 \%$ vs. $22.5 \%$ ). These results were consistent with previous studies indicating that the mutation of EGFR was associated with gender, adenocarcinoma, and smoking status $[3,4,38]$.

There were very limited studies investigating polymorphisms of different EMT-related genes expression and their relationship with carcinogenesis. Xie et al. [39] have reported lately that EMT-related gene variants, namely $A D G R F 1, N O T C H 3$, and $C D H 1$, may be involved in susceptibility to NSCLC. Cai et al. [40] earlier revealed that genetic effect of a nonsynonymous HRH4 polymorphism (rs11662595) is a loss-of-function polymorphism that results in dysfunction of HRH4 gene and attenuates the anti-EMT function of HRH4 in NSCLC. This investigation provides a promising biomarker for prognosis and therapy of NSCLC. Kim S et al. [41] also demonstrates that EMT phenotype was related to PD-L1 overexpression in pulmonary adenocarcinoma cells and patients with EMT-phenotype pulmonary adenocarcinoma may benefit from PD-1/PD-L1blocking immunotherapy. But to the detail of $C D H 1$ gene polymorphisms and their association with EGFR mutation status, no specific research was found prior to ours.

Our findings relative to association between CDH1 polymorphism and EGFR mutation status suggested CA and CA + AA genotypes of CDH1 SNP rs16260 were significantly reverse associated with EGFR mutation type in female patients with lung adenocarcinoma (AOR $=0.43,95 \% \mathrm{CI}=0.20-0.92$ and $\mathrm{AOR}=0.46,95 \% \mathrm{CI}=0.22-0.96$, respectively), as compared to the control (CC genotype). AA genotype of the same SNP also showed the same direction of association $(\mathrm{AOR}=0.72,95 \% \mathrm{CI}=0.13-3.90)$, but did not reach statistical significance. We further verified this association with the use of two EGFR hotspot mutations, namely L858R mutation and in-frame deletion mutation in exon 19, and obtained the consistent statistically significant relationship. These results may explain that $C D H 1$ variant type is less associated with EGFR mutation type especially among the female population; in the other words, CDH1 wild type (CC genotype) is more related to mutate EGFR tyrosine kinase, which is a more favorable prognosis and strongly predicts for sensitivity to EGFR-TKIs. However, the mechanism by which this SNP (rs16260) modulates the roles of female lung adenocarcinoma patients should be further investigated.

Among male lung adenocarcinoma patients, we found no statistical significance between $C D H 1$ polymorphism and EGFR mutation status. But when we further stratified them based on tumor characteristic of AJCC " $\mathrm{T}$ " classification (primary tumor size and extension), $C D H 1$ rs16260 variant type (CA + AA genotype) showed significantly reverse association as $\mathrm{T}$ classification progressed, as compared with the control type (CC genotype). This association was still seen in male patients with mutated EGFR gene. In the previous studies, downregulation of E-cadherin expression is highly associated with cancer progression and metastasis [13, 42-45]. The inclusion of other clinicopathologic parameters at molecular level should be further investigated.

In conclusion, our results suggested that E-cadherin gene $(C D H 1)$ variants are significantly reverse associated with mutation of EGFR tyrosine kinase, especially among the female patients with lung adenocarcinoma. This may be utilized as a prognostic factor for tumor size in Taiwanese patients with lung adenocarcinoma.

\section{Competing Interests}

The authors have declared that no competing interest exists.

\section{References}

[1] Wang BY, Huang JY, Cheng CY, Lin CH, Ko J, Liaw YP. Lung cancer and prognosis in taiwan: a population-based cancer registry. J Thorac Oncol 2013; 8: 1128-1135.

[2] Travis WD, Brambilla E, Nicholson AG, et al. The 2015 World Health Organization Classification of Lung Tumors: Impact of Genetic, Clinical and Radiologic Advances Since the 2004 Classification. J Thorac Oncol 2015; 10: 1243-1260.

[3] Kawaguchi T, Koh Y, Ando M, et al. Prospective Analysis of Oncogenic Driver Mutations and Environmental Factors: Japan Molecular Epidemiology for Lung Cancer Study. J Clin Oncol 2016; 34: 2247-2257.

[4] Shi Y, Au JS, Thongprasert S, et al. A prospective, molecular epidemiology study of EGFR mutations in Asian patients with advanced non-small-cell lung cancer of adenocarcinoma histology (PIONEER). J Thorac Oncol 2014; 9: 154-162.

[5] Alimperti S, Andreadis ST. CDH2 and CDH11 act as regulators of stem cell fate decisions. Stem Cell Research 2015; 14: 270-282.

[6] Beavon IRG. The E-cadherin-catenin complex in tumour metastasis. European Journal of Cancer 2000; 36: 1607-1620.

[7] Lim SC, Jang IG, Kim YC, Park KO. The role of E-cadherin expression in non-small cell lung cancer. J Korean Med Sci 2000; 15: 501-506.

[8] Kim H, Yoo SB, Sun P, et al. Alteration of the E-Cadherin/beta-Catenin Complex Is an Independent Poor Prognostic Factor in Lung Adenocarcinoma. Korean J Pathol 2013; 47: 44-51.

[9] Pećina-Šlaus N. Tumor suppressor gene E-cadherin and its role in normal and malignant cells. Cancer Cell International 2003; 3: 17.

[10] Su SC, Hsieh MJ, Yang WE, Chung WH, Reiter RJ, Yang SF. Cancer metastasis: Mechanisms of inhibition by melatonin. J Pineal Res 2017; 62: e12370.

[11] Liu X, Su L, Liu X. Loss of CDH1 up-regulates epidermal growth factor receptor via phosphorylation of YBX1 in non-small cell lung cancer cells. FEBS Lett 2013; 587: 3995-4000.

[12] Cheng HL, Lin CW, Yang JS, Hsieh MJ, Yang SF, Lu KH. Zoledronate blocks geranylgeranylation not farnesylation to suppress human osteosarcoma U2OS cells metastasis by EMT via Rho A activation and FAK-inhibited JNK and p38 pathways. Oncotarget 2016; 7: 9742-9758.

[13] Zhao C, Li X, Su C, et al. High expression of E-cadherin in pleural effusion cells predicts better prognosis in lung adenocarcinoma patients. Int J Clin Exp Pathol 2015; 8: 3104-3109.

[14] Yang YL, Chen MW, Xian L. Prognostic and clinicopathological significance of downregulated E-cadherin expression in patients with non-small cell lung cancer (NSCLC): a meta-analysis. PLoS One 2014; 9: e99763.

[15] Zhou J, Wang J, Zeng Y, et al. Implication of epithelial-mesenchymal transition in IGF1R-induced resistance to EGFR-TKIs in advanced non-small cell lung cancer. Oncotarget 2015; 6: 44332-44345.

[16] Chien MH, Chou LS, Chung TT, et al. Effects of E-cadherin (CDH1) gene promoter polymorphisms on the risk and clinicopathologic development of oral cancer. Head Neck 2012; 34: 405-411. 
[17] Chien MH, Yeh KT, Li YC, et al. Effects of E-cadherin (CDH1) gene promoter polymorphisms on the risk and clinicopathological development of hepatocellular carcinoma. J Surg Oncol 2011; 104: 299-304.

[18] Han P, Liu G, Lu X, et al. CDH1 rs9929218 variant at 16q22.1 contributes to colorectal cancer susceptibility. Oncotarget 2016; 7: 47278-47286.

[19] Siegert S, Hampe J, Schafmayer C, et al. Genome-wide investigation of gene-environment interactions in colorectal cancer. Hum Genet 2013; 132: 219-231.

[20] Smith CG, Fisher D, Harris R, et al. Analyses of 7,635 Patients with Colorectal Cancer Using Independent Training and Validation Cohorts Show That rs9929218 in CDH1 Is a Prognostic Marker of Survival. Clin Cancer Res 2015; 21: $3453-3461$.

[21] Liu TC, Hsieh MJ, Wu WJ, et al. Association between survivin genetic polymorphisms and epidermal growth factor receptor mutation in non-small-cell lung cancer. Int J Med Sci 2016; 13: 929-935.

[22] Lin CS, Liu TC, Lai JC, Yang SF, Tsao TC. Evaluating the Prognostic Value of ERCC1 and Thymidylate Synthase Expression and the Epidermal Growth Factor Receptor Mutation Status in Adenocarcinoma Non-Small-Cell Lung Cancer. Int J Med Sci 2017; 14: 1410-1417.

[23] Su SC, Hsieh MJ, Lin CW, et al. Impact of HOTAIR Gene Polymorphism and Environmental Risk on Oral Cancer. J Dent Res 2018; 22034517749451.

[24] Goldstraw P, Chansky K, Crowley J, et al. The IASLC Lung Cancer Staging Project: Proposals for Revision of the TNM Stage Groupings in the Forthcoming (Eighth) Edition of the TNM Classification for Lung Cancer. J Thorac Oncol 2016; 11: 39-51.

[25] Brouxhon SM, Kyrkanides S, Teng X, et al. Monoclonal antibody against the ectodomain of E-cadherin (DECMA-1) suppresses breast carcinogenesis: involvement of the HER/PI3K/Akt/mTOR and IAP pathways. Clin Cancer Res 2013; 19: 3234-3246.

[26] Najy AJ, Day KC, Day ML. The ectodomain shedding of E-cadherin by ADAM15 supports ErbB receptor activation. J Biol Chem 2008; 283: 18393-18401.

[27] Chan AO, Chu KM, Lam SK, et al. Soluble E-cadherin is an independent pretherapeutic factor for long-term survival in gastric cancer. J Clin Oncol 2003; 21: 2288-2293.

[28] Symowicz J, Adley BP, Gleason KJ, et al. Engagement of collagen-binding integrins promotes matrix metalloproteinase-9-dependent E-cadherin ectodomain shedding in ovarian carcinoma cells. Cancer Res 2007; 67: 2030-2039.

[29] Ahmed N, Maines-Bandiera S, Quinn MA, Unger WG, Dedhar S, Auersperg $\mathrm{N}$. Molecular pathways regulating EGF-induced epithelio-mesenchymal transition in human ovarian surface epithelium. Am J Physiol Cell Physiol 2006; 290: C1532-1542.

[30] Li Y, Tang Y, Zhou R, et al. Genetic polymorphism in the 3'-untranslated region of the E-cadherin gene is associated with risk of different cancers. Mol Carcinog 2011; 50: 857-862.

[31] Zuo JH, Zhu W, Li MY, et al. Activation of EGFR promotes squamous carcinoma SCC10A cell migration and invasion via inducing EMT-like phenotype change and MMP-9-mediated degradation of E-cadherin. J Cell Biochem 2011; 112: 2508-2517.

[32] Brouxhon SM, Kyrkanides S, Raja V, et al. Ectodomain-specific E-cadherin antibody suppresses skin SCC growth and reduces tumor grade: a multitargeted therapy modulating RTKs and the PTEN-p53-MDM2 axis. Mol Cancer Ther 2014; 13: 1791-1802.

[33] Brouxhon S, Kyrkanides S, O'Banion MK, et al. Sequential down-regulation of E-cadherin with squamous cell carcinoma progression: loss of E-cadherin via a prostaglandin E2-EP2 dependent posttranslational mechanism. Cancer Res 2007; 67: 7654-7664.

[34] Brouxhon SM, Kyrkanides S, Teng X, et al. Soluble E-cadherin: a critical oncogene modulating receptor tyrosine kinases, MAPK and PI3K/Akt/mTOR signaling. Oncogene 2014; 33: 225-235.

[35] Chen PN, Yang SF, Yu CC, et al. Duchesnea indica extract suppresses the migration of human lung adenocarcinoma cells by inhibiting epithelial-mesenchymal transition. Environ Toxicol 2017; 32: 2053-2063.

[36] Wang A, Lu C, Ning Z, et al. Tumor-associated macrophages promote Ezrin phosphorylation-mediated epithelial-mesenchymal transition in lung adenocarcinoma through FUT4/LeY up-regulation. Oncotarget 2017; 8: 28247-28259.

[37] Suda K, Tomizawa K, Fujii M, et al. Epithelial to mesenchymal transition in an epidermal growth factor receptor-mutant lung cancer cell line with acquired resistance to erlotinib. J Thorac Oncol 2011; 6: 1152-1161.

[38] Hsu $\mathrm{CH}$, Tseng $\mathrm{CH}$, Chiang $\mathrm{CJ}$, et al. Characteristics of young lung cancer: Analysis of Taiwan's nationwide lung cancer registry focusing on epidermal growth factor receptor mutation and smoking status. Oncotarget 2016; 7: 46628-46635.

[39] Xie K, Ye Y, Zeng Y, Gu J, Yang H, Wu X. Polymorphisms in genes related to epithelial-mesenchymal transition and risk of non-small cell lung cancer. Carcinogenesis 2017; 38: 1029-1035.

[40] Cai WK, Zhang JB, Chen JH, et al. The HRH4 rs11662595 mutation is associated with histamine $\mathrm{H} 4$ receptor dysfunction and with increased epithelial-to-mesenchymal transition progress in non-small cell lung cancer. Biochim Biophys Acta 2017; 1863: 2954-2963.

[41] Kim S, Koh J, Kim MY, et al. PD-L1 expression is associated with epithelial-to-mesenchymal transition in adenocarcinoma of the lung. Hum Pathol 2016; 58: 7-14.
[42] David JM, Rajasekaran AK. Dishonorable discharge: the oncogenic roles of cleaved E-cadherin fragments. Cancer Res 2012; 72: 2917-2923.

[43] Inge LJ, Barwe SP, D'Ambrosio J, et al. Soluble E-cadherin promotes cell survival by activating epidermal growth factor receptor. Exp Cell Res 2011; 317: 838-848.

[44] Higashi K, Ueda Y, Shimasaki M, et al. High FDG uptake on PET is associated with negative cell-to-cell adhesion molecule E-cadherin expression in lung adenocarcinoma. Ann Nucl Med 2017;

[45] Petrova YI, Schecterson L, Gumbiner BM. Roles for E-cadherin cell surface regulation in cancer. Mol Biol Cell 2016; 27: 3233-3244. 